\title{
Development of Competitive PCR and the QPCR System 5000 as a Transcription-based Screen
}

\author{
E. Tracey Wilkinson, ${ }^{1}$ Sela Cheifetz, ${ }^{2}$ and Stephanie A. De Grandis ${ }^{3}$
}

${ }^{1}$ Biochemical Pharmacology, Allelix Biopharmaceuticals, Inc., Mississauga, Ontario, Canada L4V 1V7

We describe the use of the quantitative PCR (QPCR) system 5000 (Perkin-Elmer) and competitive PCR in a simple and reproducible assay format for use in establishing a screen for the discovery of compounds that affect gene regulation. Insulin-like growth factor 1 (IGF-1) mRNA was chosen as an initial target to test the sensitivity and reproducibility of the QPCR System 5000 in the quantitation of PCR products generated in competitive PCR reactions. We found that with the use of sequence-specific probes, the QPCR 5000 could be used easily to distinguish between internal standard (IS) and wild-type products in PCR reactions. We were able to detect as little as twofold changes in CDNA amounts by using dilutions of total rat liver CDNA as a source of IGF-1 message. The QPCR system 5000 could be used to analyze 24 competitive PCR reactions (48 samples), single determinations, in $\sim 1$ hr. The flexibility, automation, and sensitivity of the QPCR System $\mathbf{5 0 0 0}$ makes it a useful tool to measure the transcriptional regulation of various mRNAs.
Present addresses: ${ }^{2}$ MRC Group, Periodontal Physiology, Faculty of Dentistry, University of Toronto, Toronto, Ontario, Canada M5S 1A8; ${ }^{3}$ Ministry of Agriculture, Food and Rural Affairs, Agriculture and Food Laboratory, Guelph, Ontario, Canada N1H 8]7. $n$ the past 10 years there have been significant advances in the understanding of the transcriptional regulation of genes. This information has led to the discovery of "illegitimate" transcriptional events in several disease states. ${ }^{(1)}$ Compounds affecting mRNA transcription have now entered the drug discovery and development pathways of many of the world's leading pharmaceutical companies. The challenge posed in the identification of transcription-based therapeutic leads has been to develop simple, reproducible assays that allow the user to screen large, compound libraries.

Advances in QPCR technology now allow the precise quantitation of mRNA in a single cell. ${ }^{(2-4)}$ A QPCR-based screening strategy allows the measurement of mRNA directly in very few cells or tissue. Unlike screening methods that employ reporter constructs containing only known regulatory components of the genes of interest, no prior knowledge of these components is required to quantitate mRNA levels using QPCR. In addition, this type of screen would be more flexible, as mRNA targets can be switched easily, provided the gene sequence is known, without needing to know all of the transcription regulatory components. The key feature of this technique is the use of a competitive template that is introduced into test specimens as a stringent control of all reactions. Classic methods are based on the coamplification of varying amounts of an internal standard (IS) mRNA with a constant amount of the test mRNA sample containing an unknown quantity of the mRNA of interest. The IS is amplified in the same tube and with the same primer pair as the target DNA; therefore, any differences in primer efficiency or tube-to-tube variations are eliminated. ${ }^{(2,3)}$ This method requires multiple PCR reactions for each unknown sample. Thus, a large number of PCR reactions must be processed to determine an accurate mRNA concentration in test samples.

An alternative competitive PCR strategy makes use of an external standard curve. $^{(4,5)}$ The external standard curve method allows the analysis of multiple RNA samples by comparison of unknowns with a single set of standard samples containing known amounts of the purified wild-type template of interest. All wild-type and unknown samples are spiked with a constant amount of an IS template, and a standard curve is generated by quantitation of the relative amounts of wild-type and IS products in each of the PCR reactions containing known amounts of input wild-type template. The amount of wild-type target in a sample of unknown concentration is determined by direct comparison of the ratio wild-type target to IS to the standard curve obtained from the known standard samples. As many unknown samples can be analyzed with one standard curve, the method becomes a powerful tool for the transcription-based screening of the therapeutic effects of drugs on eukaryotic cells.

Various methods have been used for the quantitation of PCR products. Traditional gel-based methods tend to be manually time-consuming, with low throughput and low sensitivity. Radioactive-based detection increases the sensitivity but carries with it those problems inherent in the use of radioactivity, in- 
cluding contamination of equipment, disposal problems, and health and safety issues. The QPCR System 5000 (Perkin Elmer) is an automated system that makes use of electrochemiluminescence for detection of PCR products as described previously. ${ }^{(6-9)}$ In this system, one of the PCR primers is biotinylated at the $5^{\prime}$ end to allow capture onto streptavidin-coated magnetic beads. A complementary probe is designed that is $5^{\prime}$-labeled with the electrochemiluminescent label Tris (2,2'-bipyridine) ruthenium (II) chelate (TBR). After hybridization and capture, the samples are loaded into the QPCR system 5000, where an oxidizing reaction, initiated by a voltage sweep and involving the TBR label and tripropylamine (TPA) (present in the assay buffer), results in the generation of a luminosity signal. There is minimal manual labor involved with the QPCR system 5000. Previous studies have shown that this detection system is linear over a range of greater than three orders of magnitude and can detect PCR products in the attomole range. ${ }^{(6)}$ As the system is automated, variation resulting from sample handling is minimized while throughput surpasses what can be achieved through classical detection methods.

In this report the feasibility of utilizing the QPCR system 5000, and an external standard curve method of competitive QPCR, to establish a gene expression-based screen was evaluated. We first tested whether competitive PCR products could be easily differentiated on the QPCR 5000 on the basis of sequence differences by use of sequencespecific probes. Second, as many mRNAs are induced only two- to threefold, ${ }^{(10,11)}$ we determined whether the screen allowed the detection of two- to threefold changes in mRNA levels. Insulin-like growth factor 1 (IGF-1) expression in rat liver was chosen as our test system. The general applicability of the system to the screening of compound repositories is discussed.

\section{MATERIALS AND METHODS}

\section{Test Samples}

Total RNA from rat liver was isolated by the guanidine isothiocyanate method as described previously. ${ }^{(12)}$ cDNA was prepared by reverse transcription of total RNA, in the presence of $5 \mathrm{mM} \mathrm{MgCl}_{2}, 1 \times$
PCR buffer II (50 mM KCl, $10 \mathrm{~mm}$ Tris$\mathrm{HCl}$ at $\mathrm{pH} 8.3), 1 \mathrm{~mm}$ each of dGTP,dATP,dCTP, and dTTP, $1 \mathrm{U} / \mu \mathrm{l}$ of RNase inhibitor, $2.5 \mathrm{U} / \mu \mathrm{l}$ of Moloney murine leukemia virus (M-MLV) reverse transcriptase (RT), $2.5 \mu \mathrm{M}$ random hexamers (all reagents from GeneAmp RNA PCR Kit, Perkin-Elmer), and $10 \mu \mathrm{l}$ of $0.5 \mu \mathrm{g} / \mu \mathrm{l}$ total RNA from rat liver in a final volume of $100 \mu \mathrm{l}$. Samples were incubated at $42^{\circ} \mathrm{C}$ for $1 \mathrm{hr}$, followed by $5 \mathrm{~min}$ at $99^{\circ} \mathrm{C}$ to inactivate the RT. Test samples were made by serially diluting the resulting cDNA.

\section{Probes and Primers}

Primers and probes were synthesized inhouse on an Applied Biosystems 391 DNA synthesizer. Primer sequences were selected as follows: IGF-1 primer 1, 5'-biotin-CATCTCTTCTACCTGGCA3'; IGF-1 primer 2, 5'-TTGTTTCCTGCACTTCCTCTA-3' [118-135 and 525505 of rat IGF-1 sequence, ${ }^{(13)}$ respectively]. Primer 1 was biotinylated using MMT-biotin-CEP (Penninsula Laboratories) to allow the capture of PCR product onto steptavidin-coated magnetic beads. The amplified PCR product sizes were 357 and $546 \mathrm{bp}$ for the wild-type and the IS, respectively.

Probes hybridizing to wild-type or IS PCR products were as follows: wild-type probe, 5'-AAGCAACACTCATCCACAATGCCCGTCTGT-3'; IS probe, 5'-ATCCACAATGTCTTCCATGTCCTCCTCCTC-3'; [317-288 of the rat IGF-1 sequence ${ }^{(13)}$ and 237-208 of Clontech's neutral DNA sequence, ${ }^{(14)}$ respectively]. The probes were 5 '-labeled with TBR (Perkin-Elmer).

\section{Construction of Purified is and Wild-type Template}

We constructed the IGF-1 IS using Clontech's PCR Mimic Construction Kit, according to the manufacturer's directions. ${ }^{(14)}$ Two composite primers were designed containing IGF-1 primer 1 or primer 2 sequence attached to a 20 -nucleotide sequence that hybridizes to opposite strands of Clontech's neutral DNA fragment. The target gene primer sequences become incorporated into the IS during the primary amplification generating a PCR product that can be designed to differ from the wild-type template by size (for gel-based analysis) as well as sequence, depending on the lo- cation of the primer sequence hybridizing to the neutral DNA.

The wild-type template was prepared by amplifying rat liver cDNA using IGF-1 primer 1 and 2 . The resulting PCR product was $357 \mathrm{bp}$ in size rather than the 408-bp transcript predicted by the location of the IGF- 1 primers. This is attributable to the splicing out of a 52-bp sequence $^{(13)}$ in the major IGF-1 transcript present in our samples. This was confirmed using a probe specific to the missing 52-bp sequence that gave very low signal on the QPCR System 5000 (data not shown). PCR product from the primary reaction was then diluted $1: 100$ and reamplified. Both the wild-type and the IS PCR products were purified by passage through Chroma Spin TE-100 columns (Clontech). The yield was estimated by running the products on an agarose gel and visually comparing the band intensity to that of known quantities of pGEM DNA markers (Promega). ${ }^{(14)}$ A 100 amoles/ $\mu$ l stock was made from which serial dilutions were prepared.

\section{Competitive PCR Amplifications}

Each PCR reaction contained $2 \mathrm{~mm}$ $\mathrm{MgCl}_{2}, 1 \times$ PCR buffer II, $0.2 \mathrm{~mm}$ each of dGTP, dTTP, dCTP, and dATP, $0.15 \mu \mathrm{M}$ of each primer, 1.25 units of AmpliTaq DNA polymerase, (GeneAmp RNA PCR core reagents, Perkin-Elmer), $2 \mu \mathrm{l}$ of a known amount of IGF-1 wild-type template, and $2 \mu \mathrm{l}$ of IS (see figure legends for exact concentrations used) in a total volume of $50 \mu \mathrm{l}$. Standards and test samples were run in parallel on the GeneAmp PCR System 9600 (Perkin-Elmer). The cycling parameters were as follows: Thirty cycles of $94^{\circ} \mathrm{C}$ for $30 \mathrm{sec}, 50^{\circ} \mathrm{C}$ for $30 \mathrm{sec}, 72^{\circ} \mathrm{C}$ for $1 \mathrm{~min}$; followed by a final extension at $72^{\circ} \mathrm{C}$ for $7 \mathrm{~min}$ and a $4^{\circ} \mathrm{C}$ soak.

\section{QPCR 5000 Detection}

Aliquots of each PCR reaction were used in separate hybridizations with either the wild-type or IS sequence-specific TBR-labeled probe. Under optimized conditions, each reaction contained $1 \mu \mathrm{l}$ of the amplified PCR reaction, 10 pmoles of sequence-specific probe labeled with TBR, and $1 \times$ PCR buffer II in a total volume of $50 \mu \mathrm{l}$. Samples were denatured at $95^{\circ} \mathrm{C}$ for $2 \mathrm{~min}$ followed by hybridization to the specific probes at $55^{\circ} \mathrm{C}$ for 5 
min, using the GeneAmp PCR system 9600 . Products from the hybridization reaction were captured onto $15 \mu$ l of a bead suspension containing $2 \mu \mathrm{g} / \mu \mathrm{l}$ of $4.5 \mu \mathrm{m}$ magnetic streptavidin-coated dynabeads (Perkin-Elmer), giving a bead to product ratio of 15:1 ( $\mathrm{vol} / \mathrm{vol})$. Tubes were incubated for $30 \mathrm{~min}$ at room temperature with manual shaking every 5 min to prevent settling of the beads. The total volume was then transferred to $12 \times 75-\mathrm{mm}$ polypropylene tubes and loaded into the carousel of the QPCR System 5000 for analysis.

\section{RESULTS AND DISCUSSION}

\section{Optimization}

Initial conditions for the hybridization and capture reactions were supplied by Perkin-Elmer. A $5 \mu \mathrm{l}$ aliquot of the PCR product was hybridized to 10 pmoles of TBR-labeled probe at $60^{\circ} \mathrm{C}$ for $5 \mathrm{~min}$. Streptavidin-coated beads $(15 \mu \mathrm{l})$ were then added, and the products were captured at $55^{\circ} \mathrm{C}$ for $20 \mathrm{~min}$. These conditions were optimized for our particular probes and target sequences by varying the hybridization and capture conditions. Variables tested were length and temperature of the hybridization and capture steps, probe concentration, and streptavidin-coated bead and PCR product amounts. We found that room temperature capture and an increased bead to product ratio of $15: 1$ ( $\mathrm{vol} / \mathrm{vol}$ ) from 3:1 were important, resulting in an increase in luminosity values from 500 units [which is at the low end of the dynamic range $\left.{ }^{(6,7)}\right]$ to $2000-3000$ units. The use of optimal hybridization and capture conditions provides the user with lower PCR product detection limits. Thus, it is important that these conditions be optimized for each new PCR product.

\section{Sensitivity and Linearity}

The limit of detection, precision, and linearity of the QPCR System 5000 were analyzed using the bead-bound standards supplied with the system according to the manufacturer's directions. ${ }^{(15)}$ It is important that the screen be sensitive enough to detect small differences in mRNA levels allowing for detection of weak positives. Using the bead standards, the QPCR System 5000 was capable of detecting $<100$ amoles of product. A detection limit of $\sim 2$ amoles for the QPCR System 5000 has been reported previously which is comparable to that observed with radioisotopes. ${ }^{(7)}$ The intra-assay precision with the bead standards was calculated to give a coefficient of variation (CV) of $2.6 \%$ with a linear range of over three logs of initial input cDNA. The capacity to detect PCR product over a range of three orders of mag-

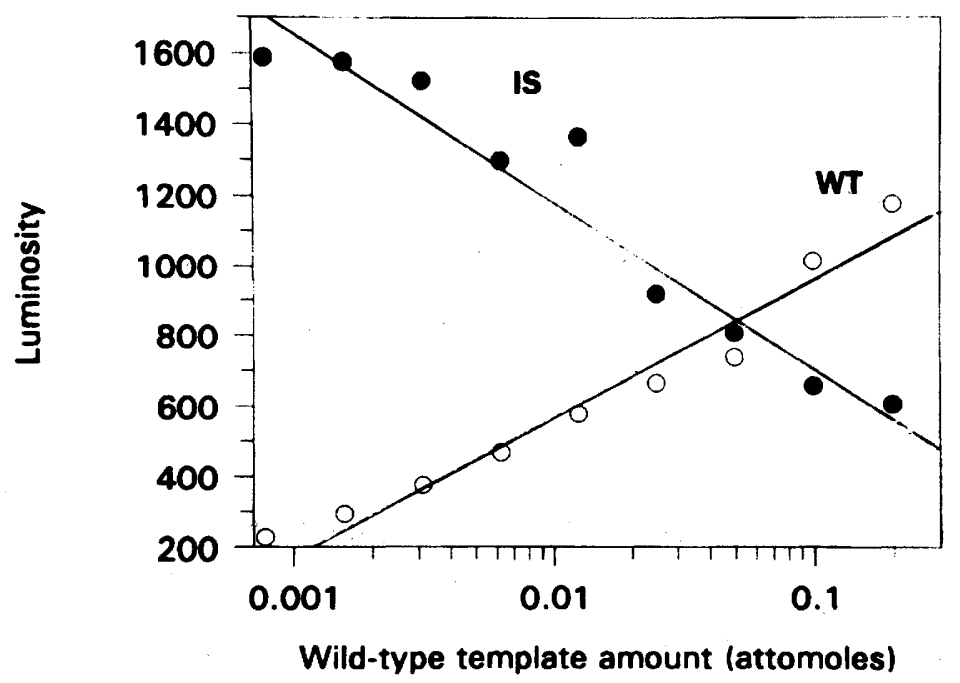

FIGURE 1 Titration of IGF-1-purified wild-type template with a constant amount of IGF-1 IS. 0.2 amoles of IGF-1 IS was added to PCR reactions containing twofold serial dilutions from 0.2 amoles to $7.8 \times 10^{-4}$ amoles of purified wild-type template. After amplification, PCR products were analyzed on the QPCR System 5000 . The data are plotted as luminosity value vs. amoles of input wild-type on a linear-log scale. (O) IGF-1 IS product; $(\bigcirc)$ IGF-1 wild-type product.

nitude enhances a gene-based screen, as it is desirable that the screen accommodate a wide range of product amounts that may be generated from test samples.

\section{Competitive PCR}

Known amounts of IGF-1-purified wildtype template were serially diluted and coamplified with a constant amount of IGF-1 IS template. The wild-type template was diluted with an initial starting amount of either $10^{-1}$ or $10^{-3}$ amoles/ $\mu l$, with a constant amount of IGF-1 IS template equivalent to the wild-type starting dilution, depending on the amount of cDNA used in the test samples. The amplified products corresponded to the predicted product sizes as determined by agarose gel electrophoresis and comparison with pGEM DNA markers (data not shown). The PCR products were then analyzed on the QPCR System 5000 using sequence-specific probes for the wild-type and the IS PCR products. One can see that as the wild-type product increases, the amount of IS product decreases demonstrating that the two products are competing in the amplification reaction.

The probes for wild-type and IS PCR products were first tested for cross-reactivity by hybridizing samples that contained wild-type product alone with the IS sequence-specific probe, or IS product with the wild-type sequence-specific probe. The resulting luminosity values from the QPCR System 5000 were roughly equal to the background signal of 67 (defined as the mean of 22 measurements of no template PCR reactions plus $3 \times$ the standard deviation). The IS and wild-type probes hybridized to their respective PCR products generated in the competitive PCR reactions as shown in Figure 1. The corresponding standard curve was linear. Repeat analysis of the same competitive reactions 1 month later yielded a similar standard curve (Fig. 2).

Intra-assay variation of experimental samples was also tested by analyzing five replicate samples. A CV of $12 \%$ was determined. One would expect a higher variation in the experimental samples compared with the bead standards because of variation introduced with the addition of the hybridization and capture steps. There may also have been pipetting inaccuracies associated with both of these steps. Intra-assay variation 


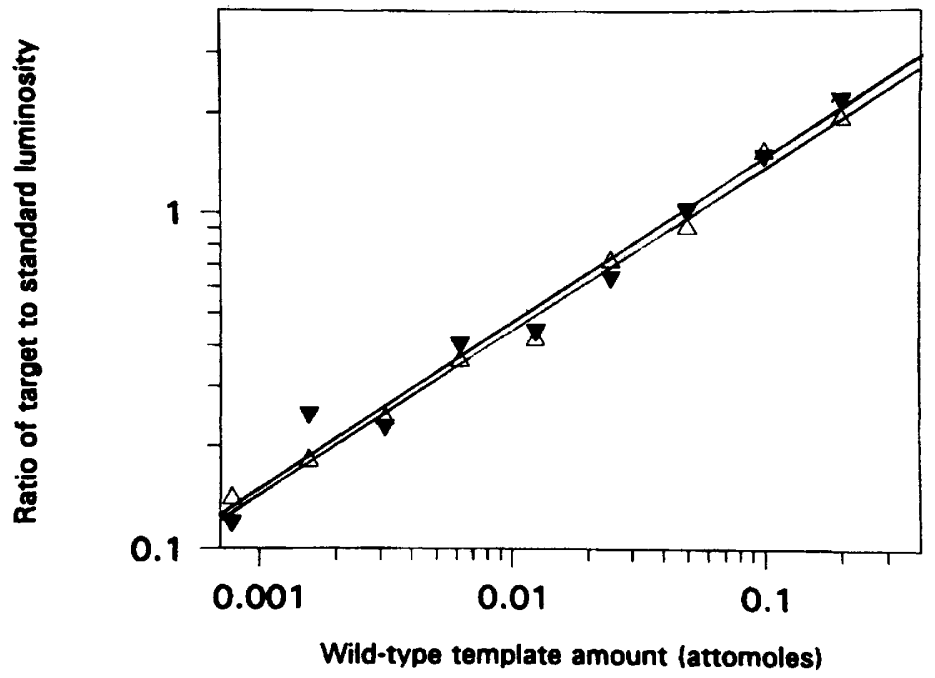

FICURE 2 Standard curve of the competitive PCR experiment shown in Fig. 2 . The standard curve is constructed by calculating the ratio of the wild-type product over the IS product and plotting the result on a log-log scale against attomoles of input wild-type template present in the PCR reaction. $(\triangle)$ First analysis of standard curve samples; $(\nabla)$ repeat analysis of standard curve samples. may be improved by increasing the volume of test sample in the hybridization assays. We have since moved to using 5 $\mu l$ of the PCR reaction. To keep our optimized bead to product ratio of $15: 1$, we are using less cycle numbers to reduce product amount or diluting the product when working at higher cycle numbers so that $5 \mu \mathrm{l}$ of diluted product would be equivalent to $1 \mu \mathrm{l}$ of undiluted product. We found that variation among replicate readings of the same sample on the QPCR System 5000 was minimal (3\% CV). Therefore, one reading per tube was all that was required. This allowed the processing of 24 competitive PCR reactions with two different probes, (48 samples), in $1 \mathrm{hr}$. Variation attributable to

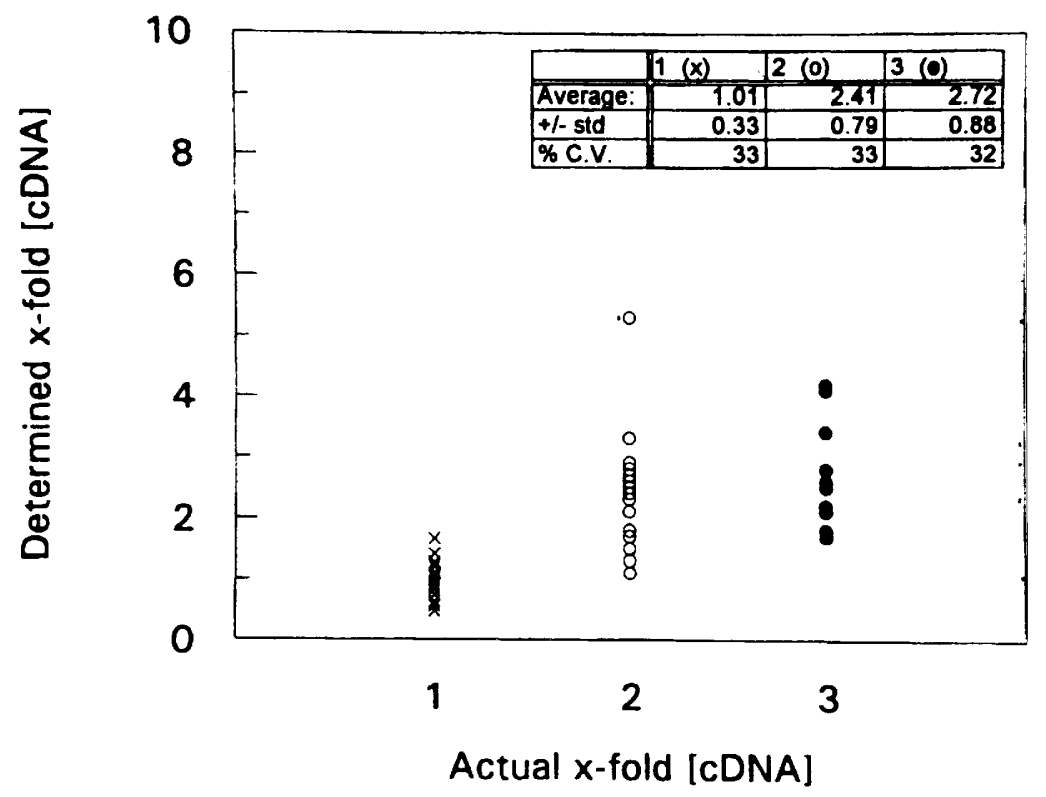

FICURE 3 Scattergram of one-, two-, and threefold changes in test cDNA. The basal values, calculated from replicate samples of the test CDNA and plotted at 1 on the $x$-axis, are defined as $x_{\mathrm{i}} / x_{\mathrm{av}}$ where $x_{\mathrm{i}}$ is the determined attomole/ $\mu$ l value for each individual replicate. The average, S.D. and percent $\mathrm{CV}$ for each set is also shown. handling of the sample and washing between samples was reduced as it was done internally by the machine.

An important prerequisite for a gene expression screen is the accurate detection of two- to threefold changes in cDNA levels. To test the sensitivity of the assay, a master cDNA stock was serially diluted either two- or threefold and amplified with a constant amount of the IS template. The ratio of wild-type to IS PCR product was determined for the test samples, and attomole values of input cDNA were determined using a standard curve (as in Fig. 2). Theoretically, if the initial cDNA concentration between samples differed by twofold, the resulting attomole values should also have differed by twofold. The determined and actual differences ( $x$-fold) are shown in Figure 3 . The average, standard deviation, and percent $\mathrm{CV}$ for each $x$-fold difference is also shown. The system allowed us to detect twofold differences in input IGF- 1 cDNA with a $33 \% \mathrm{CV}$. In the context of our application for the assay, a relatively high percent $\mathrm{CV}$ was acceptable. We found that most of the variability was attributable to PCR amplification and not to the QPCR System 5000 PCR product analysis (data not shown). This was confirmed by DiCesare et al., ${ }^{(7)}$ who found that only $2 \%$ intraday error was contributed to the total PCR assay precision by the QPCR System 5000 . When a 1.3 cutoff value defined as no $x$-fold increase in cDNA (see Fig. $3 ; 1 \pm 0.33$ s.D.) was used, we calculated a false-negative rate of $4 \%$ and a false-positive rate of $25 \%$ when determining twofold differences in input IGF-1 cDNA. These levels are acceptable for a primary screen where a low rate of false negatives is important, whereas any false positives would likely be caught in a secondary screen. It is important that all sources of assay variability be accounted for in the determination of false-positive and falsenegative rates. Because the values given here were obtained starting with CDNA, they may change once variation at the cDNA synthesis step is determined. Although the mean value for the threefold increase was higher than that of the twofold increase, the difference was not statistically significant because of the high percent CV of the assay. Where increases differed by twofold or greater, preliminary data indicate that a detectable difference in the level of increase could be measured (data not shown). Neverthe- 
less, within the context of this screen, both the twofold and threefold increases would have correctly scored as positives because both were, on average, significantly different from basal.

\section{SUMMARY}

We have demonstrated that competitive PCR followed by detection on the QPCR system 5000 can be used in gene expression-based screens. The methodologies are sensitive enough to detect as little as twofold differences in cDNA levels over a large dynamic range using acceptable false-positive and false-negative rates for a primary screen. The screen is easily adaptable to any target provided the target DNA sequence is known. Therefore, multiple targets can be detected in the same assay. The variation observed is acceptable for use in a screening laboratory and may be improved through further optimization of the PCR reactions. The QPCR System 5000 can be used to detect PCR products that have been amplified for relatively few cycles, which is not always possible with gel-based detection methods. ${ }^{(16)}$ Because the detection system is based on sequence differences, it is not necessary to have a size difference between the IS and wild-type products (although we chose to have one). This has the benefit of eliminating any potential inequalities in amplification rates because of size differences between products. ${ }^{(17)}$

Post-PCR detection using the QPCR System 5000 is automated, requires minimal manual labor, and also allows the user to directly capture and store data. Currently, the automation of the PCR process is our next challenge. Several excellent examples of PCR automation are referred to the reader. ${ }^{(18-20)}$

\section{ACKNOWLEDGMENTS}

We thank Suzanne Presseault for her technical assistance, Raya Kuperman for the synthesis of the probes and primers used, and Alan Koop of Perkin-Elmer for the use of the QPCR System 5000 and for technical assistance. We also thank Dr. Martin Sumner-Smith for helpful discussions and guidance. This research was supported by grant STP-BIO 395939 awarded by the Strategic Technologies Program (STP) Canada.
Received December 27, 1994; accepted in revised form March 6, 1995.

\section{REFERENCES}

1. Peterson, M.G., V.R. Baichwal. 1993. Transcription factor based therapeutics: Drugs of the future? Tibtech 11: 11-18.

2. Wang, A.M., M.V. Doyle, and D.F. Mark. 1989. Quantitation of mRNA by the polymerase chain reaction. Proc. Natl. Acad. Sci. 86: 9717-9721.

3. Becker-André, M. and K. Hahlbrock. 1989. Absolute mRNA quantification using the polymerase chain reaction (PCR). A novel approach by a PCR aided transcript titration assay (PATTY). Nucleic Acids Res. 17: 9437-9446.

4. Zacher, V., R.A. Thomas, and A.S. Goustin. 1993. Absolute quantification of target DNA: A simple competitive PCR for efficient analysis of multiple samples. $\mathrm{Nu}$ cleic Acids Res. 21: 2017-2018.

5. Telenti, A., P. Imboden, and D. Germann. 1992. Competitive polymerase chain reaction using an internal standard: application to the quantitation of viral DNA. $J$. Virol. Methods 39: 259-268.

6. Wages, J.M. Jr., L. Dolenga, and A.K. Fowler. 1993. Electrochemiluminescent detection and quantitation of PCR-amplified DNA. Amplifications 10: 1-6.

7. DiCesare, J., B. Grossman, E. Katz, E. Picozza, R. Ragusa, and T. Woudenberg. 1993. A high-sensitivity electrochemiluminescence-based detection system for automated PCR quantitation. BioTechniques 15: 152-157.

8. Yang, H., J.K. Leland, D. Yost, and R.J. Massey. 1994. Electrochemiluminescence: A new diagnostic and research tool. ECL detection technology promises scientists new "yardsticks" for quantification. BioTechnology 12: 193-194.

9. Blackburn G.F., H.P. Shah, J.H. Kenten, J. Leland, R.A. Kamin, J.Link, J. Peterman, M.J. Powell, A. Shah, D.B. Talley, S.K. Tyagi, E. Wilkins, T-G. Wu, and R.J. Massey. 1991. Electrochemiluminescence detection for development of Immunoassays and DNA probe assays for clinical diagnostics. Clin. Chem. 37: 1534-1539.

10. Drake, M.T., J.J. Baldassare, C.L. McConkey, E.A. Gonzalez, and K.J. Martin. 1994. Parathyroid hormone increases the expression of receptors for epidermal growth factor in UMR 106-01 cells. Endocrinology 134: 1733-1737.

11. Sutherland, M.K., L.G. Rao, J.N. Wylie, A. Gupta, H. Ly, J. Sodek, and T.M. Murray. 1994. Carboxyl-terminal parathyroid hormone peptide (53-84) elevates alkaline phosphatase and osteocalcin mRNA levels in SaOS-2 cells. J. Bone Miner. Res. 9: 453458.

12. Chomczynski, P. and N. Sacchi. 1987. Sin- gle step method of RNA isolation by acid guanidinium thiocyanate-phenol-chloroform extraction. Anal. Chem. 162: 156159.

13. Roberts, C.T., S.R. Lasky, W.L. Lowe, W.T. Seaman, and D. LeRoith. 1987. Molecular cloning of rat insulin-like growth factor I complementary deoxyribonucleic acids: Differential messenger ribonucleic acid processing and regulation by growth hormone in extrahepatic tissues. Mol. Endocrinol. 1: 243-248.

14. Clontech Mimic Construction Kit manual, Palo Alto, CA. 15. QPCR System 5000 Manual, Perkin-Elmer Corp. 16. Murphy, L.D., D.E. Herzog, J.B. Rudick, A.T. Fojo, and S.E. Bates. 1990. Use of the polymerase chain reaction in the quantitation of mdr-1 gene expression. Biochemistry 29: 10351-10356.

17. Chelly, J., D. Montarras, C. Pinset, Y. Berwald-Netter, J.C. Kaplan, and A. Kahn. 1990. Quantitative estimation of minor mRNAs by cDNA-polymerase chain reaction. Application to dystrophin mRNA in cultured myogenic and brain cells. Eur. J. Biochem. 187: 691-698.

18. Nickerson, D.A., R. Kaiser, S. Lappin, J. Atewart, L. Hood, and U. Landegren. 1990. Automated DNA diagnostics using an ELISA-based oligonucleotide ligation assay. Proc. Natl. Acad. Sci. 87: 8923-8927.

19. Civitello, A.B., S. Richards, and R.A. Gibbs. 1992. A simple protocol for the automation of DNA cycle sequencing reactions and polymerase chain reactions. $J$. DNA Seq. Mapping 3: 17-23.

20. Harrison, D., C. Baldwin, and D.J. Prockop. 1993. Use of an automated workstation to facilitate PCR amplification, loading agarose gels and sequencing of DNA templates. BioTechniques 14: 8897.

Received December 27, 1994; accepted in revised form March 6, 1995. 


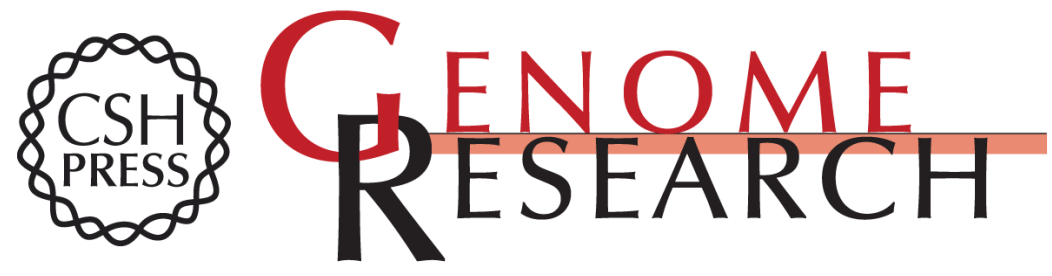

\section{Development of competitive PCR and the QPCR system 5000 as a transcription-based screen.}

E T Wilkinson, S Cheifetz and S A De Grandis

Genome Res. 1995 4: 363-367

References This article cites 18 articles, 3 of which can be accessed free at: http://genome.cshlp.org/content/4/6/363.full.html\#ref-list-1

\section{License}

Email Alerting

Receive free email alerts when new articles cite this article - sign up in the box at the Service top right corner of the article or click here.

\section{Affordable, Accurate Sequencing.}

To subscribe to Genome Research go to: https://genome.cshlp.org/subscriptions 